\title{
So close, so far? Part-time employment and its effects on gender equality in Italy and Spain ${ }^{1}$
}

\author{
Lara Maestripieri and Margarita León
}

\section{Introduction}

In comparison with most other European countries, part-time employment does not make up a high percentage of employment in Spain and Italy. Part-time work by men is negligible in both countries and is also limited for women. A different picture is drawn, however, when other forms of non-standard employment are considered. When compared with countries such as France, the Netherlands, Sweden or the UK, both Italy and Spain show a high level of involuntary work, either in the form of fixed-term or permanent part-time contracts. In Spain, involuntary part-time work increased steadily during the economic crisis, in parallel with the sharp rise in unemployment, consolidating at about $16 \%$ of all employment once the crisis ended. It has now become a form of underemployment and is a way for employers to avoid dismissals.

In this chapter, the authors assess the extent to which the process of de-standardisation in labour contracts has turned part-time work into a form of precarious employment in these two countries rather than a way to ease work-family conflict. They aim to analyse insider-outsiders cleavages among women working part-time in Italy and Spain, assuming intersectionality as an analytical strategy (Collins, 2015). To do so, they use an inter-categorical approach to intersectionality, as put forward by McCall (2005). This approach implies a strategic use of intersectional categories in order to stress the multiple inequalities that arise when different dimensions of disadvantage collide (McCall, 2005; Winker and Degele, 2011; Walby et al, 2012). The idea is to look at the multiplicative effects that specific intersections might have on the general condition of disadvantage suffered by women in order to understand the dynamics that lie beneath the integration of women 
in non-standard working positions. The intersectional approach puts in question the intra-group similarity of women, highlighting the differences that occur among women with different educational levels, of different ages and having different childcare responsibilities.

In highly dualised labour markets, the chances for part-timers to escape from insider-outsider dynamics are limited. Yet, while the 'voluntariness' of part-time work is, in itself, a reflection of the type of part-time work available, there are multiple differences among various groups of workers that require more nuanced observations. The focus of this chapter is on the differences between women with regard to access to the labour market and their different working arrangements. The authors will show how particular combinations of educational level, age and household composition increase marginality within the labour market.

Italy and Spain belong to the 'corporate' welfare regime cluster that has certain 'Mediterranean traits' distinct enough, according to some authors, to fall under an altogether different typology. Despite the centrality of occupational welfare, and because of a certain degree of fragmentation in social provision, the Southern European welfare model has always performed rather poorly in the development of universal services and family policy. As is to be expected in a conservative welfare regime, the state relies on the 'caring family' but does not do so through specific policies that preserve the role of the traditional family and, specifically, the role of women within the family, as in Continental Europe. What Saraceno (1994) has termed 'unsupported familialism' refers to a limited capacity of these welfare states to foster employment and social policies that enhance women's chances to reconcile their work and family life (such as, for instance, part-time work). The lack of effective work-family balance mechanisms and care policies has a negative impact on fertility dynamics and the participation of women in the labour market.

In the last two to three decades, the two countries have gone through what Rueda (2015: 109) calls the protectionist processes of industrialisation, where labour market regulations to protect insiders have contributed to reduced labour productivity and high income inequality. In many countries, the deregulation and flexibilisation of employment has led to an across-the-board increase of atypical forms of employment, with the subsequent deepening of insider-outsider labour market dynamics (Emmenegger et al, 2012). The origins and reasons for this labour market dualisation are beyond the aim of this chapter. However, it is nonetheless essential to understand: (1) the extent to which flexibility conveys a very different meaning 
in countries of the South; and (2) the specific ways in which it affects women and young people. In Spain, the rapid increase in female employment has coincided with a very strong increase in occupational polarisation, which means that differences between women belonging to different occupational groups have widened over recent years. In Italy, labour market deregulation has always been proposed 'at the margins', meaning that those who were already employed when the new regulation was implemented have not been affected by the worsening of working conditions (for instance, more flexible dismissal procedures) (Firinu and Maestripieri, 2018). Differences due to gender and age have been widening. As in Spain, women and young people are more exposed to precariousness and underemployment; differently from Spain, however, women and young people are only partially protected by a higher educational level (Villa, 2010).

In both countries, part-time employment is right at the heart of this process of differentiation between categories of workers with unequal access to social and employment rights, such as unemployment benefits and old-age pensions. In a recent case, for instance, the European Court of Justice declared that the Spanish legislation on part-time employment was not compliant with the European Union (EU) directive on equal treatment for men and women in matters of social security. ${ }^{2}$

The implication for gender equality is that more women than men are affected by atypical employment and, together with the young and workers of foreign origin, women suffer the consequences of an increasingly precarious labour market. As will be shown later in this chapter, the incidence of involuntary part-time work is much higher among women than men. Following gender, the probability of having involuntary part-time work or a fixed-term contract is highly determined by age, skill level and type of occupation. For this reason, it is important to use an intersectional approach that takes this socioeconomic and socio-demographic differentiation into account.

From a sociological perspective, the term 'non-standard employment contract' is used to refer to any contract that deviates from the fulltime permanent dependent contract that is taken to be the standard (Bosch, 2006). In this analysis, non-standard forms of work thus include fixed-term contracts, part-time contracts and non-dependent self-employment. Several combinations of non-standard work can be given with multiple layers of de-standardisation (ie part-time contracts that are also temporary contracts). Each has a different distribution by gender and by age: self-employment is more diffuse among adult men; part-time work is more common among adult women; and part-time 
and fixed-term contracts are equally shared among young workers of both sexes.

This section provides an overview of part-time employment and other forms of non-standard work in the two countries on which the authors focus. To help situate Italy and Spain within a wider European comparative framework, the authors also look at the situation in France, Sweden, the Netherlands and the UK. In the latter three countries, women's non-standard employment is mainly composed of part-time work voluntarily chosen by the person (see Table 3A.1). Other forms of non-standard employment, such as temporary, selfemployment or involuntary work, are less common, comparatively speaking. In Italy, Spain and, to some degree, France, non-standard employment moves away from the ideal of 'good work' as it is mostly involuntary fixed-term and part-time employment.

In Spain, the hegemonic form of non-standard employment is a fixed-term job (see Table 3A.1). Almost $90 \%$ of non-standard contracts held by men and about $60 \%$ of the contracts held by women are fixedterm contracts; it is the only country with more women on a fixedterm than a part-time contract. The temporary nature of contracts in Spain is evident when the contracts held by younger generations are analysed: more than $70 \%$ of the total number of employed workers under 24 years of age are temporary workers, compared with about 55\% each in France, Italy, the Netherlands and Sweden. ${ }^{3}$ The difference with other countries is salient as well for older workers: $38.5 \%$ in Spain versus about 20\% in the other countries for 25-34 year olds, and 23\% versus about 10\% for 35-49 year olds. As already argued, this high level of temporary work has serious consequences for labour market polarisation. Spain is one of the countries where having a fixed-term contract has the highest associated penalty regarding larger gaps in earnings per hour (Conde Ruiz and Marra de Artínano, 2016). Additionally, 58\% of non-standard employment in Spain is involuntary.

In Italy, on the contrary, self-employment is the most diffuse nonstandard form of employment: in 2016, almost one worker in five was self-employed, whereas in countries such as Spain, the Netherlands and the UK, only 15\% are self-employed, and in France and Sweden, the percentages are even lower (about 10\%). Nevertheless, this type of contract is strongly gendered in all the countries considered as it is the most popular form of non-standard work for men: self-employment represents $64 \%$ of total non-standard work in Italy and the UK, and about $40 \%$ in the other countries. Non-standard employment among women is mostly represented by part-time work strongly characterised by involuntariness, as in Spain. 
The level of part-time work in the two countries is low in comparative terms, especially in Spain (see Table 3A.2). With the exception of the Netherlands and the UK, migrants are more likely to be employed on a part-time basis, but the difference compared with the native population is especially strong in Italy. Young adults under 25 years of age are usually more exposed to part-time employment, but only in Italy and Spain is there a clear linear correlation between age and part-time work. In all the other countries, part-time work grows among workers older than 50 who are making their exit from the labour market, but this does not occur in Spain and Italy. Education is linearly correlated with part-time work in all the countries: loweducated workers are the most exposed to this contract, but in Spain and Italy, high-skilled workers have particularly low levels of part-time work. Finally, what really distinguishes Spain and Italy is that there is a relatively lower proportion of men employed part-time, the majority being under 34 years old.

In comparison with other countries in Europe, however, Spain, Italy and, to a certain extent, France distinguish themselves by having a higher level of female involuntary non-standard work, meaning those part-time workers who would prefer to work full-time (see Figure 3.1). As a matter of fact, Southern European countries have

Figure 3.1: Share of part-time work that is involuntary, by gender, 15-64 year olds
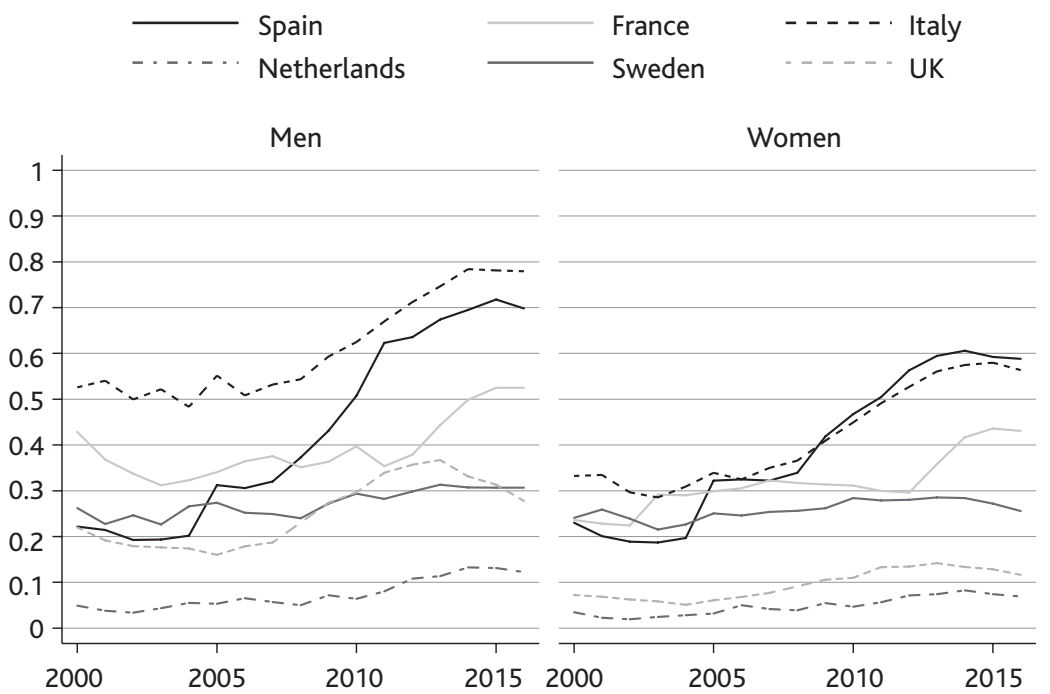

Graphs by gender

Source: Authors' own elaboration on the European Labour Force Survey (2000-16) 
witnessed the substantial growth of involuntariness during the years of the economic crisis, affecting both women and men. Among those working part-time in Italy and Spain in 2016, more than 65\% were doing so involuntarily, that is, the majority of part-timers would rather work full-time. The level of involuntary part-time workers is thus much higher in Italy and Spain than in the other countries included in our comparison and the difference has grown in the last 10 years (45.2\% in France, 34.6\% in Sweden, 16.8\% in the UK and 13.1\% in the Netherlands).

Involuntary part-time workers can be considered to be sub-employed as their condition is of partial unemployment since their working potential is not entirely satisfied by the labour market (Bodnár, 2018). According to the Spanish Labour Force Survey (EPA), the chances of involuntary part-timers moving to a permanent position are small (about 17\%); thus, part-time work does not seem to represent a stepping stone to more standard forms of employment. Rather, parttime work represents one of the main dimensions through which we detect 'bad jobs' (Nicolaisen et al, Chapter 1, this volume) and by which dualisation has been implemented in Southern European labour markets (Rueda, 2015).

\section{Origins of part-time work in Italy and Spain}

The timing of the influx of women into the labour market in Italy and Spain might have been detrimental to the development of goodquality part-time work. As Ellingsaeter and Leira (2006) argue, the entry of a large number of women into paid employment in the Nordic countries in the 1970s and 1980s, many of whom took up part-time employment, coincided with favourable conditions for the introduction of labour regulations that ensured equal rights for parttimers. A few decades later, however, similar favourable conditions were non-existent further south. Italy and Spain have historically had very low rates of female employment. Prior to 1990, the female activity rate was below or just above $30 \%$, about 20 percentage points lower than in other European countries. Both countries have since started to slowly catch up, although the growth rate has been more spectacular in Spain than in Italy.

Spain departed sharply from these low levels in the mid-1990s, with the rate of female employment increasing to $41.2 \%$ and $55.3 \%$ in 2000 and 2007, respectively (Eurostat online database 4 : 15-64). While both female and male unemployment increased rapidly during the most recent economic crisis, activity rates have not decreased, which 
indicates a stable pattern of participation in the labour market that does not fluctuate with the economic cycle or family circumstances, which was the case in the past.

Part-time work was not introduced to foster female employment. In fact, in 1980, part-time employment in Spain was heavily restricted to specific groups of workers (the unemployed and young workers under 25 years old). Only in 1984, with the first statutory reform, was the option of part-time work opened up to the entire workforce. Even then, no social or political actor advocated an expansion of part-time work as a way to develop good working opportunities for women (Ibáñez, 2011). In Italy, the first law on part-time employment was not enacted until the mid-1980s. Prior to this law (L. 863/1984), there were sporadic and unsystematic reductions of working schedules that were applied in the context of a legal vacuum to meet the rising need for flexibility. Even in cases where trade unions opposed the new law, it established arrangements concerning part-time work through national collective agreements (Santucci, 2017).

In both countries, national legislation on part-time work has subsequently been amended to comply with the European directive (97/81/CE). However, none of the labour market reforms implemented in either Italy or Spain have succeeded in presenting forms of reduced working time that are attractive to employees. Rather, labour market reforms over the last three decades have helped in many different ways to increase dualisation by maintaining high levels of protection for a core group of insiders while allowing for the expansion of poorly protected employment at the margins. In other words, while the road to increasing internal flexibility, that is, 'good' part-time work as a way to ease the tensions between work and care (or life more generally), has never been travelled, external flexibility at the contract level, whether in fixed-term employment, agency work or involuntary part-time work, has been on a continuous upward trend since the mid-1990s. This form of flexibility, proposed as a way forward in the context of high unemployment and sluggish economic growth, reinforces, rather than alleviates, tensions between family life and work (Muffels and Wilthagen, 2011) and ends up being a key dualisation mechanism in itself. Within the framework of the most recent Italian reform, the Jobs Act (Decree 34/2014), parttime contracts were further liberalised (Dlgs 81/2015). Employers can now add to the number of hours established in a part-time contract by up to $25 \%$ in the form of overtime. At the same time, however, the new regulation offers full-time workers the chance to apply for a working-time reduction for personal reasons (own illness or the illness 
of a family member, having a disabled relative in the household or having children under 13 years old in the household). Furthermore, the law now gives workers the possibility to use their parental leave to temporarily work part-time, that is, to work up to $50 \%$ fewer hours within the limits of the parental leave (10 months shared between the two parents until the child's 12th birthday). It is quite revealing that these new measures regarding part-time work were included within the decree that regulates employment contracts (Dlgs 81/2015) and not in the decree that deals specifically with work-family conciliation measures (Dlgs 80/2015) (Santucci, 2017).

\section{Intersectional analysis}

The following analysis uses microdata collected for the European Labour Force Survey (2005-16). It identifies trends in time and differences in the composition of non-standard employment in the two countries. ${ }^{5}$ Comparing the two countries is somewhat interesting since despite their apparent similarity, they exhibit different patterns in terms of integrating women into the labour market.

Given reduced numbers, the authors decided to include only women and exclude men from the analysis since the detailed observation of trends pertaining to all the intersectional categories would have been statistically difficult. The migrant working population usually has different patterns of labour market integration, which require a specifically oriented analysis. To reduce the complexity of the analysis presented in this chapter, it was decided to focus on the native population only. Furthermore, the analysis focuses on women of childbearing age (25-49 years). Above and below this age group, part-time employment is a residual phenomenon in Southern Europe.

Microdata also allow the creation of a series of typologies that explore the characteristics of women's labour force participation by taking into account: first, their ability to access the labour market on the basis of their paid work time; and, second, the type of their non-standard working arrangements. Table 3A.5 distinguishes among standard, non-standard and involuntary non-standard work: the first category includes all workers who work full-time with a permanent contract; the second category includes all non-standard workers that have voluntarily chosen a non-standard job (including self-employment and fixed-term and part-time contracts); and the third category includes all part-timers and fixed-term workers that are employed in a non-standard job because it was not possible to find an equivalent standard job. Levels of involuntariness among self-employment might 
be underestimated: in the European Labour Force Survey, there is no question asking a self-employed person if they would have rather worked as a dependent worker.

Tables $3.1 \mathrm{a}$ and $3.1 \mathrm{~b}$ focus on different types of part-time employment, with the idea of analysing how different groups of women are distributed within certain categories at risk of marginalisation (Nicolaisen et al, Chapter 1, this volume), namely: marginal parttime work (Hakim, 1997), including all those part-timers that work less than 10 hours/week; involuntary part-time work, that is, part-time contracts accepted because it was impossible to find an equivalent fulltime job; and bogus part-time work, that is, persons who officially declare themselves as working part-time but are, in fact, working more than 30 hours/week on average. This latter category is derived from the concept of bogus self-employment, as introduced by Pedersini and Coletto (2010). This is a practice that, as Bodnár (2018) points out, has been liberalised in Southern Europe in recent years thanks to recent reforms in the labour market but that might cover practices of potential contractual abuses.

Marginal and bogus part-time work are treated independently according to why the person has accepted a reduced hours schedule (for care reasons or involuntarily), on the assumption that their actual condition in the labour market is a potential risk in itself for the welfare of that person. In the first case - marginal part-time work there is a potential risk of becoming working poor (Hallerod et al, 2015); in the second case - bogus part-time work - there is a potential risk of covering exploitative undeclared work (Firinu, 2015).

The last category that we take in account in our analysis is parttime work for care reasons; in this case, a reduced working schedule is chosen voluntarily to cope with care responsibilities. Despite its voluntary nature, we consider that part-time work in this case might constitute a potential source of gender inequality as almost no man opts for part-time work because of family responsibilities. It is also important to highlight that even when part-time work is voluntarily chosen by the person, as in this case, a reduced working schedule is a potential source of economic dependency: working part-time provides a lower individual income, lower hourly pay and reduced career opportunities in the future as employers perceive it as less career-oriented (Maestripieri, 2015). Moreover, less paid hours might result in lower social protection given a reduction in social security contributions. Nevertheless, we do not include this type of parttime work in the group of part-timers at risk of marginalisation; in itself, voluntary part-time work chosen for care obligations cannot 
be considered as a condition risking labour market marginalisation (Nicolaisen et al, Chapter 1, this volume).

Three periods of time are considered in the analysis: before the economic crisis (2005-08), during the acute crisis period (2009-12) and the post-crisis years (2013-16). During the last decade, parttime work in Southern Europe has grown, especially its involuntary component. This is in line with the dualisation hypothesis: rates of non-standard work in general and involuntary part-time work in particular are congruent with a marginalisation strategy that provides employers with a source of cheap labour, mostly offered to women and young people (Kalleberg, 2008). It can hardly be interpreted as a reconciliation strategy offered by employers to retain workers with a preference for reduced working hours (Kalleberg, 2008).

For the empirical analysis, the authors developed a classification that simultaneously takes into account the workers' educational level (low $=$ ISCED $^{6} 1-2 ;$ medium $=$ ISCED 3-4; high $=$ ISCED 5-8), their age (25-34 year olds and 35-49 year olds) and gender. The resulting classification comprises 12 groups. All the gender gaps in the following section are calculated by subtracting the percentages of women from the percentages of men. The scope is to test the assumption that the marginal position of women in the labour market is evidenced by part-time employment, measured in terms of how many children under the age of 14 are present in the household. Age or education (as sources of dualisation in labour market) are important explanatory factors; we hypothesise that they drive labour market outcomes more than family obligations.

\section{Access to the labour market and standard work}

Before going in-depth into the analysis of the quality of women's employment, it is interesting to highlight how Italy and Spain differ in terms of women's participation in the labour market, focusing first on the population that is currently not in employment (see Tables 3A.3a and 3A.3b). First, education counts (see Table 3A.3a): over $50 \%$ of young and adult women with a low-skill profile are inactive in the two countries. Still, Italian women with a lower educational level are more likely to be inactive when compared to Spanish women with the same age. Conversely, there is a relative advantage of young women holding high-skilled positions in Spain compared with Italy (their inactivity is $26.9 \%$ for Spain and $37.8 \%$ for Italy). Among adult women, however, the situation is reverted $(22.4 \%$ and $16.8 \%$ in Spain and Italy, respectively). Education differentials explain the Spanish 
women's higher labour market participation compared to Italy: in Spain, half of the women have a tertiary education (53.5\% among the young; $45.8 \%$ among adults), while in Italy, only one out of every five adult women have a tertiary education (33.1\% among the young).

Family obligations impact on labour market participation as well, but the impact of children on women's employment is mediated by their age and education. The analysis of the distribution of gender gaps by the number of children under 14 years old in the household (see Table 3A.3b) makes it clear that the difference in terms of inactivity is not only a matter of family responsibilities: childcare responsibilities only magnify a situation of disadvantage among women compared to men that becomes more evident when women have a low educational background. Men and women are equally participating in the labour market only in Spain and only if they are young and childless: just one child is enough to increase women's inactivity in both countries, but the magnitude of the gender gap is determined by age and education, and it is more pronounced in Italy.

As well as being less employed than men, women also work fewer hours (see Tables 3A.4a and 3A.4b). Gaps may be interpreted as a persisting division of roles between partners: when there are children involved, households tend to follow a more traditional division of labour - men increase hours of paid work while women reduce their working hours. The higher the number of children in the household, the less paid work women take up; the correlation between the number of children and women working less is more evident among the lower educated and stronger in Italy. This interpretation is nevertheless not entirely satisfactory as even high-skilled childless young women work about three hours per week less than men. A concurrent interpretation regards the role of involuntary part-time work in determining women's involvement. Figures 3.2 and 3.3 show how involuntary non-standard employment has grown in all groups during the crisis but that the growth has been stronger for women and young people.

Figures 3.2 and 3.3 confirm the lower quality of the jobs undertaken by women and young people. There is no evident difference between Spain and Italy; however, Spain has a higher rate of involuntary nonstandard employment given the wider diffusion of temporary jobs. Men are more likely to have more standard employment and were better able to maintain their standard contracts even during the crisis. Women, on the contrary, are more likely to have non-standard employment; the last few years also show a clear trend towards involuntary work at the detriment of voluntary non-standard jobs. 
Figure 3.2: Levels of standard and non-standard employment before, during and after the economic crises, by gender, 25-49 year olds, Spain and Italy

Standard ES Spain

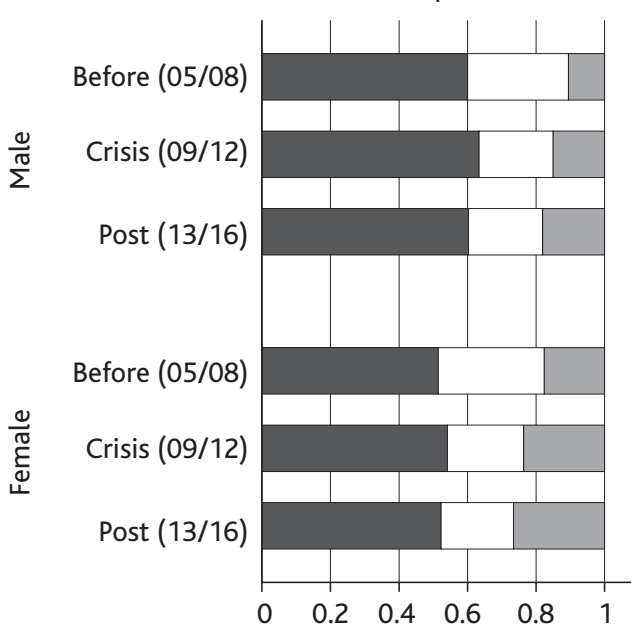

Voluntary non-standard non-standard

IT Italy

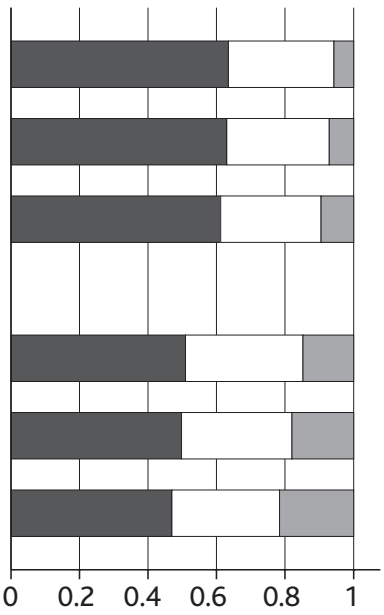

Source: Authors' own elaboration from the European Labour Force Survey (2005-16)

Figure 3.3: Levels of standard and non-standard employment before, during and after the economic crises, by age, Spain and Italy

Standard ES Spain

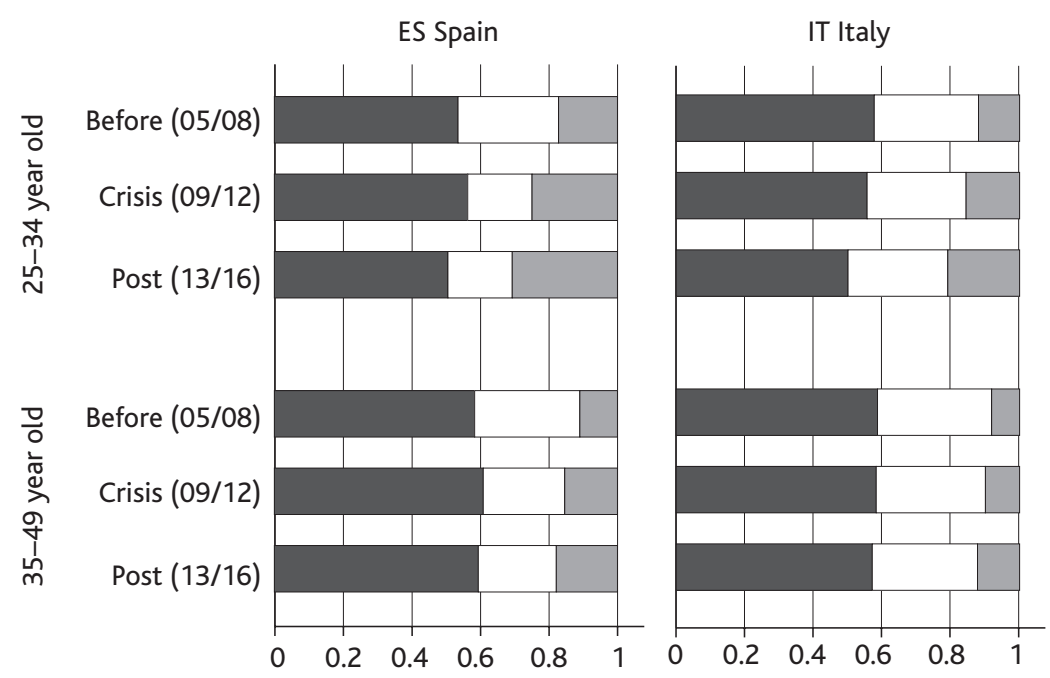

Voluntary non-standard
Involuntary non-standard

Source: Authors' own elaboration from the European Labour Force Survey (2005-16) 


\section{What characterises workers in involuntary non-standard jobs?}

There is extensive literature which demonstrates that non-standard jobs are associated with worse social and economic conditions (Maestripieri, 2015). The data presented in Table 3A.5 confirm that when a person is involuntarily employed in a non-standard job, segmentation and occupational segregation is high. First of all, voluntary non-standard work is mostly carried out by self-employed workers. Unfortunately, the European Labour Force Survey data do not provide information on the voluntariness of self-employment, which is one of the most important types of non-standard jobs, especially for adult men. Thus, it cannot be established whether freelancers who are now active in the labour market have been pushed into independent jobs or whether they were attracted to self-employment by better working opportunities (Pedersini and Coletto, 2010). As a consequence, rates of voluntary non-standard employment might be overestimated among adult men.

Second, of the total number of workers in fixed-term employment, involuntary job-takers represent $81.6 \%$ in Italy and $88.2 \%$ in Spain. Similarly, $63.8 \%$ of part-timers in Spain and 52\% in Italy are involuntary part-timers. Indicators of segmentation show the greater exposure of involuntary non-standard workers to underemployment (42.2\% in Spain and 14.1\% in Italy of non-standard workers would like to work more hours) and the reduced investment of employers in their human capital, as demonstrated by the low access to in-work training (more pronounced in Italy). Involuntary job-takers are mostly skilled and unskilled service workers in women's segregated sectors, such as traditional services (ie retail, accommodation and restaurants), care and education. Quite remarkably, there is a minor but not negligible percentage of $18 \%$ of involuntary non-standard workers who are employed in advanced business services. Among professionals and managers, involuntary non-standard workers represent $18.3 \%$ and $13.4 \%$ in Spain and Italy, respectively. This evidence questions traditional theories of labour market segmentation (Yoon and Chung, 2016).

Focusing only on involuntary part-timers (see Table 3A.6), our empirical evidence shows how this phenomenon has an intersectional dimension. First, even if it is true that involuntariness in part-time work is higher among men, it still remains a residual phenomenon affecting one in every 10 young workers and one in every 20 adult workers, especially when they are low educated. Second, involuntary 
part-time work among women is not homogeneously distributed across groups: Italian women are more exposed than Spanish women, and young women are more exposed than adult women. Among the adult population, there is a linear correlation between education and involuntary part-time work: adult women with higher education are the least exposed to the phenomenon in all the intersectional categories.

\section{The impact of children on part-time types}

The percentage of part-time employment in total employment rises when there is at least one child in the family, with different percentages in Italy and Spain. In both countries, the lowest percentage of parttime employment in total employment is found among tertiaryeducated adult women with no children (see Table 3.1a). Among the lower-educated young and adult women, the percentages of parttimers grow, especially when women have childcare responsibilities (40.5\% in Spain; $46.2 \%$ in Italy) (see Table 3.1b). However, highereducated women with children are more likely to voluntarily choose part-time work, while lower-educated women are in the majority involuntarily employed on a part-time basis even when there is at least one child in the family (about $46 \%$ for young adults and about $38 \%$ for adults).

Childcare responsibilities influence the reasons behind the choice of part-time work among women but only partially the quality of part-time employment that women undertake. In fact, Tables 3.1a and $3.1 \mathrm{~b}$ show how the percentage of women working part-time for care reasons varies significantly in the intersectional categories. However, the types of part-time work that the authors considered to be at possible risk of marginalisation (involuntary, marginal and bogus part-time work) still represented over $70 \%$ of the total number of workers in part-time employment in the case of childless women and over $50 \%$ in cases where there is a child in the household. Women with a tertiary education are less likely to work with a part-time contract at risk of marginalisation (eg involuntary part-time, bogus part-time or marginal part-time); when they have children, their risk is lower compared to less-educated women, especially when they are older than 35 years. Nevertheless, they are still more likely to be bogus part-time employed than their childless counterparts, that is, working more than 30 hours per week while officially being employed on a part-time basis. In total, over $50 \%$ of part-timers can still be considered at risk even among those who possess the highest human capital. 
Table 3.1a:Types of part-time employment among childless women aged 25-49 years old, by intersectional categories (age, education), Spain and Italy (\%)

\begin{tabular}{lccccccc}
\hline & $\begin{array}{c}\text { Part } \\
\text { time }\end{array}$ & Care & Marginal & Involuntary & Bogus & $\begin{array}{c}\text { Total } \\
\text { marginal }\end{array}$ & $\begin{array}{c}\% \\
\text { total }\end{array}$ \\
\hline Spain & & & & & & & \\
Young adult (25-34) & & & & & & & \\
Low educated & 3.5 & 0.8 & 12.9 & 67.9 & 14.9 & 95.7 & 21.6 \\
Medium educated & 13.4 & 0.7 & 15.5 & 57 & 13.3 & 85.8 & 23.4 \\
High educated & 11.4 & 0.5 & 16.8 & 58.7 & 12.6 & 88.1 & 22 \\
Totals by age & 10.8 & 0.5 & 16 & 59.6 & 13.1 & 88.7 & 22.2 \\
\hline Adult (35-49) & & & & & & & \\
Low educated & 13.4 & 6.2 & 25.3 & 48 & 7.2 & 80.5 & 33.3 \\
Medium educated & 15.5 & 3.5 & 14.3 & 54.1 & 12.5 & 80.9 & 18.5 \\
High educated & 12.9 & 4.9 & 14.4 & 52.6 & 15.2 & 82.2 & 11.6 \\
Totals by age & 13.7 & 5.3 & 19.8 & 50.6 & 10.6 & 81.1 & 19.5 \\
\hline Italy & & & & & & & \\
Young adult(25-34) & & & & & & & \\
Low educated & 7.1 & 2.5 & 9 & 63.6 & 17.7 & 90.3 & 36.2 \\
Medium educated & 11.3 & 1.5 & 7.6 & 59.1 & 20.4 & 87.1 & 31.3 \\
High educated & 12.3 & 0.9 & 15.3 & 51.4 & 20.1 & 86.8 & 22.7 \\
Totals by age & 11.2 & 1.4 & 10.5 & 56.9 & 20 & 87.4 & 28 \\
\hline Adult (35-49) & & & & & & & \\
Low educated & 10 & 9.1 & 14.2 & 51.3 & 15.4 & 80.9 & 37.7 \\
Medium educated & 12.4 & 13.6 & 8.3 & 43.8 & 21.9 & 74 & 25 \\
High educated & 15.2 & 7.1 & 15.1 & 42.7 & 19.9 & 77.7 & 16.3 \\
Totals by age & 11.9 & 10.8 & 11.7 & 46.6 & 19 & 77.4 & 26.4 \\
\hline Note: Pat-time & & & & & & & \\
\hline
\end{tabular}

Note: Part-time at risk of marginalisation is the sum of marginal part-time (less than 10 hours per week), involuntary part-time (part-timers who would like to work full-time but did not find a full-time job) and bogus part-time (official part-time contract when workers usually work more than 30 hours per week)

Source: Authors' own elaboration on the European Labour Force Survey (averages 2013-16)

Further inferences can be made about childless women on the basis of the survey data. In the case of childless women, the role of parttime work for care reasons is almost negligible. Only a minority of childless women (not more than 15\% in any category) voluntarily choose to work on a part-time basis. Apart from this involuntariness, they are also affected by marginal part-time work (on average, $15 \%$ in the two countries) and bogus part-time work (15\% in Spain; $20 \%$ in Italy). Bogus part-time work is especially high among highereducated adult women, perhaps because of an abusive use of this type of contract by employers. The level of education does not seem to protect against marginal part-time work, which is nonetheless 
Table 3.1b:Types of part-time employment among women with children aged 25-49 years old, by intersectional categories (age, education), Spain and Italy (\%)

\begin{tabular}{|c|c|c|c|c|c|c|c|}
\hline & $\begin{array}{l}\text { Part } \\
\text { time }\end{array}$ & Care & Marginal & Involuntary & Bogus & $\begin{array}{c}\text { Total } \\
\text { marginal }\end{array}$ & $\begin{array}{c}\% \\
\text { total }\end{array}$ \\
\hline \multicolumn{8}{|l|}{ Spain } \\
\hline \multicolumn{8}{|l|}{ Young adult (25-34) } \\
\hline Low educated & 6.7 & 23.2 & 14.1 & 46.1 & 9.8 & 70 & 39.9 \\
\hline Medium educated & 9 & 34.6 & 12.4 & 32.7 & 11.3 & 56.4 & 33.3 \\
\hline High educated & 8.9 & 36.3 & 10.2 & 27.9 & 16.7 & 54.8 & 23.6 \\
\hline Totals by age & 8.1 & 30.7 & 12.3 & 36.3 & 12.6 & 61.2 & 30.9 \\
\hline \multicolumn{8}{|l|}{ Adult (35-49) } \\
\hline Low educated & 9.1 & 21.7 & 21.9 & 38.6 & 8.7 & 69.2 & 40.5 \\
\hline Medium educated & 10.4 & 35.1 & 11.5 & 30.2 & 12.8 & 54.5 & 30.4 \\
\hline High educated & 10.8 & 37.4 & 8.2 & 24.2 & 19.5 & 51.9 & 22 \\
\hline Totals by age & 10.2 & 32.2 & 13 & 29.8 & 14.7 & 57.6 & 27.5 \\
\hline \multicolumn{8}{|l|}{ Italy } \\
\hline \multicolumn{8}{|l|}{ Young adult (25-34) } \\
\hline Low educated & 3 & 23.5 & 13.9 & 46 & 13.6 & 73.5 & 46 \\
\hline Medium educated & 4 & 30 & 6.6 & 34.7 & 24.6 & 65.9 & 41.8 \\
\hline High educated & 5.2 & 31.7 & 8.8 & 30.3 & 24 & 63.1 & 28.9 \\
\hline Totals by age & 4.1 & 29 & 8.6 & 36.1 & 22.2 & 66.9 & 38.8 \\
\hline \multicolumn{8}{|l|}{ Adult (35-49) } \\
\hline Low educated & 5 & 25.7 & 13.6 & 38.6 & 17.1 & 69.3 & 46.2 \\
\hline Medium educated & 5.4 & 36.7 & 5.9 & 25 & 27 & 57.9 & 41.1 \\
\hline High educated & 5.6 & 33.2 & 9.4 & 22.1 & 29.6 & 61.1 & 28.6 \\
\hline Totals by age & 5.3 & 33.3 & 8.5 & 27.4 & 25.4 & 61.3 & 38.1 \\
\hline
\end{tabular}

Note: Part-time at risk of marginalisation is the sum of marginal part-time (less than 10 hours per week), involuntary part-time (part-timers who would like to work full-time but did not find a full-time job) and bogus part-time (official part-time contract when workers usually work more than 30 hours per week).

Source: Authors' own elaboration on the European Labour Force Survey (averages 2013-16)

prevalently involuntary. Bogus part-time work is especially frequent in Italy, while marginal part-time work is more frequently found in Spain. However, involuntarily part-timers remain the most frequent category of part-timers in the two countries for all the intersectional types identified in the analysis if the woman has no children.

\section{Conclusions}

In many countries, part-time employment developed during the 1970s and 1980s in parallel with the incorporation of women into the labour market in large numbers. At a time when caring responsibilities were 
placed squarely upon the shoulders of women, part-time work was put forward as an attractive solution to women of childbearing age who wanted to work but could not do so on a full-time basis. Although this has created strong gender wage gaps, working conditions have been by and large good. The discussion of part-time employment in Italy and Spain, however, takes a very different direction. In these two countries, part-time work, together with other forms of nonstandard employment, expanded much later as a response to severe constraints on the core of the labour market, such as strong restrictions on the dismissal of permanent workers. Non-standard contracts, such as fixed-term and part-time work, started to rise in this context of labour market rigidity and strong hindrances to job growth. Hence, it is virtually impossible to disassociate the evolution of part-time work from the logic of labour market dualisation. This is, indeed, very different from how part-time work developed in other European countries. Part-time employment as a long-term activation strategy in the Netherlands, for instance, allowed for a positive inclusion of non-standard work in the form of equal treatment in wages and access to social security rights. Dutch trade unions played a key role in the creation of this win-win scenario of working time and organisational flexibility (Visser and Hemerijck, 1997; Hemerijck, 2013). In the two Southern European countries, the security element of flexible working arrangements has always been conspicuously absent. The power of insiders in organised labour and the political weakness of Left cabinets have been major hindrances to the introduction of more secure forms of labour market activation (Beramendi, 2015). Employers' demand for greater external flexibility at the contract level has been accommodated only for non-core occupational groups and new entrants. In both countries, national legislation on part-time work has subsequently been amended to comply with the European directive (97/81/CE) but this has still not prevented part-time work from becoming an expression of deepening dualisation dynamics.

As this chapter has shown, a large majority (over 60\%) of parttime workers in Italy and Spain have not voluntarily chosen to work part-time. If they were given the chance, they would work more hours. The proportion of part-time workers who consider their status involuntary has increased with the economic crisis as it offers a way for employers to reduce labour costs and secure flexibility. It could be argued that, overall, part-time work in these two countries did not become an option for workers who prefer to work shorter hours, but became a way to make employment more flexible in the context of increasing labour precariousness. 
Using an intersectional perspective, the authors investigated the possible interlocking effects of disadvantage that occur when multiple factors intersect to define the living and working conditions of individuals. Through their common set of structural features but differentiated outcomes, the comparison between Italy and Spain is interesting on several counts. The analysis presented in this chapter has shown the relative advantage of women with high skill levels in both countries, although more so in Spain. Highly skilled women have lower employment gaps and are penalised less when they become mothers. In almost every category, gender gaps are stronger for women with low to medium education levels, including the number of hours worked. The presence of children in the household magnifies a situation of disadvantage that characterises all women, linked to educational level in Spain and age group in Italy, where the youngest adults and lowest educated are the most exposed to nonstandard contracts. Only a minority of part-time contracts are chosen for reasons of care: over $80 \%$ of female part-timers with no children are affected by marginalised working conditions in part-time work, including extremely reduced working hours (less than 10 hours/week), involuntariness and an officially stated part-time contract when the worker usually works more than 30 hours per week. Recent years have shown an increasing level of involuntariness behind non-standard employment, while involuntary non-standard employment magnifies the exposure to segregation and segmentation that characterises these types of contracts.

Involuntary part-time work is growing among all categories of workers, especially among young women without children. Bogus part-time work is growing among medium and highly skilled women with young children but, at least, marginal part-time work (ie working less than 10 hours/week) remains stable and residual. While the younger generations are the most affected by this dynamic, a significant difference between the two countries is the extent to which education protects women against involuntary part-time work in Spain but not in Italy, where the disadvantage is driven by age.

Reflecting upon the typology presented in the introductory chapter, the evolution of part-time employment in Italy and Spain places these two countries in the 'marginalised part-time workers' type. The lagged position of the two Southern European countries in relation to their economic development, democratic consolidation and welfare state expansion made them miss the train of the flexicurity momentum in other European countries. The involuntary character of most parttime work signals a supply-side-driven development with the worst 
possible consequences for workers in the farthest part of the prevailing insider-outsider divide.

\section{Notes}

1 This chapter has received funding from the EU's Horizon 2020 research and Innovation Programme under the Marie Skłodowska-Curie Grant Agreement No 747433.

2 Ms Espadas Recio v Servicio Público de Empleo Estatal (SPEE). Ms Espadas Recio had been working part-time for a company for 12 years. When the unemployment insurance was calculated, the public service considered only the days of the week worked in respect of which contributions had been paid. The Court of Justice ruled that this was discriminatory against women because the vast majority of 'vertical' part-timers are women (Court of Justice of the EU Press Release No XX/17, 9 November 2017, available at: https://curia.europa.eu/jcms/upload/docs/application/pdf/2017-11/ cp170116en.pdf).

3 Given the low barriers to dismissal among permanent workers in the UK, the rate of temporary work in this country is particularly low in comparison.

4 See: https://ec.europa.eu/eurostat/data/database

5 The analysis starts in 2005 as the data collected for the Italian Labour Force Survey prior to that date followed a different data-collection strategy that make comparisons between the waves before and after 2004 potentially difficult.

6 ISCED is the International Standard Classification of Education and it is used to compare educational levels across countries. For more information see: https://ec.europa.eu/eurostat/statistics-explained/index.php/ International_Standard_Classification_of_Education_(ISCED)

\section{References}

Beramendi, P. (2015) 'Constrained partisanship and economic outcomes' in P. Beramendi, S. Häusermann, H. Kitschelt and H. Kriesi (eds) The politics of advanced capitalism, Cambridge: Cambridge University Press, pp 333-56.

Bodnár, K. (2018) 'Recent developments in part-time employment'. Available at: https://goo.gl/SL5pcH

Bosch, G. (2006) 'Working time and the standard employment relationship', in J.-Y. Boulin, M. Lallement, J.C. Messenger and F. Michon (eds) Decent working time: New trends, new issues, Geneva: International Labour Office, pp 41-64.

Collins, P.H. (2015) 'Intersectionality's definitional dilemmas', Annual Review of Sociology, 41(1): 1-20. 
Conde Ruiz, J.I. and Marra de Artínano, I. (2016) 'Gender gaps in the Spanish labour market', Estudios sobre la Economía Española 2016/32. Available at: http://documentos.fedea.net/pubs/eee/eee2016-32.pdf Ellingsaeter, A.L. and Leira, A. (2006) (eds) Politicising parenthood in Scandinavia: Gender relations in welfare states, Bristol: The Policy Press.

Emmenegger, P., Hausermann, S., Palier, B. and Seeleib-Kaiser, M. (2012) The age of dualization: The changing face of inequality in deindustrializing societies, Oxford, Oxford University Press.

Firinu, A. (2015) 'La flessibilità irregolare: un fenomeno grigio della regolazione del lavoro', Sociologia del Lavoro, 138: 37-54.

Firinu, A. and Maestripieri, L. (2018) 'Lavoro marginale', in A. Zucca and C. Croce (eds) Lavoro marginale e nuove vulnerabilità, Milano: Giangiacomo Feltrinelli Editore.

Hakim, C. (1997) 'Sociological perspective on part-time work', in H.P. Blossfeld and C. Hakim (eds) Between equalization and marginalization: Women working part-time in Europe and the United States of America, Oxford: Oxford University Press, pp 22-70.

Hallerod, B., Ekbrand, H. and Bengtsson, M. (2015) 'In-work poverty and labour market trajectories: poverty risks among the working population in 22 European countries', Journal of European Social Policy, 25(5): 473-88.

Hemerijck, A. (2013) Changing welfare states, Oxford: Oxford University Press.

Ibáñez, Z. (2011) 'Part-time employment in Spain: a victim of the "temporality culture" and a lagging implementation', in A.M. Guillén and M. León (eds) The Spanish welfare state in European context, London: Ashgate, pp 165-86.

Kalleberg, A.L. (2008) 'Nonstandard employment relations and labour market inequality', in D.B. Grusky (ed) Social stratification: Class, race and gender in sociological perspective, Boulder, CO: Westview Press, pp 562-75.

Maestripieri, L. (2015) 'Gendering social vulnerability. The role of labour market de-standardisation and local welfare', in D. Kutsar and M. Kuronen (eds) Local welfare policy making in European cities, Berlin: Springer, pp 51-67.

McCall, L. (2005) 'The complexity of intersectionality', Signs: Journal of Women in Culture and Society, 30(3): 1771-800.

Muffels, R. and Wilthagen, T. (2011) 'Defining flexicurity indicators for the public sector in Europe', 1 March. Available at SSRN: https://ssrn.com/abstract=1968845 or https://dx.doi.org/10.2139/ ssrn.1968845 
Pedersini, R. and Coletto, D. (2010) Self-employed workers: Industrial relations and working conditions, Dublin: Eurofond. Available at: https:// goo.gl/rU9Dhn

Rueda, D. (2015) 'The origins of dualism', in P. Beramendi, S. Häusermann, H. Kitschelt and H. Kriesi (eds) The politics of advanced capitalism, Cambridge: Cambridge University Press.

Santucci, R. (2017) 'Il contratto di lavoro part-time tra Jobs Act (decreto legislativo n. 81/2015) e diritto giurisprudenziale'. Available at: https://goo.gl/ffiiRa

Saraceno, C. (1994) 'The ambivalent familism of the Italian welfare state', Social Politics, 1(1): 60-82.

Villa, P. (2010) 'La crescita dell'occupazione femminile: la polarizzazione tra stabilità e precarietà', Lavoro e diritto, XXIV(3): 343-58.

Visser, J. and Hemerijck, A. (1997) A Dutch miracle: Job growth, welfare reform and corporatism in the Netherlands, Amsterdam: Amsterdam University Press.

Walby, S., Armstrong, J. and Strid, S. (2012) 'Intersectionality: multiple inequalities in social theory', Sociology, 46(2): 224-40.

Winker, G. and Degele, N. (2011) 'Intersectionality as multi-level analysis: dealing with social inequality', European Journal of Women's Studies, 18(1): 51-66.

Yoon, Y. and Chung, H. (2016) 'New forms of dualization? Labour market segmentation patterns in the UK from the late 90s until the post-crisis in the late 2000s', Social Indicators Research, 128(2): 609-31. 


\section{Appendix}

Table 3A.1: Labour market indicators in the six countries - population aged 15-64, percentages, 2016

\begin{tabular}{|c|c|c|c|c|c|c|}
\hline & $\begin{array}{l}\text {.5 } \\
\text { 离 }\end{array}$ & 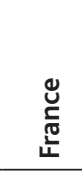 & $\frac{\vec{\pi}}{ \pm}$ & 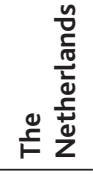 & 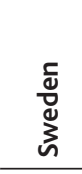 & 弚 \\
\hline Inactivity rate (women) & 31 & 32.5 & 44.8 & 24.9 & 19.8 & 28.1 \\
\hline Inactivity rate (men) & 20.5 & 24.6 & 25.2 & 15.6 & 16.1 & 18 \\
\hline Unemployment (women) & 21.5 & 9.9 & 12.9 & 6.5 & 6.7 & 4.8 \\
\hline Unemployment (men) & 18.2 & 10.4 & 11.1 & 5.7 & 7.6 & 5.1 \\
\hline $\begin{array}{l}\text { Rate of non-standard work in } \\
\text { employment (women), of which: }\end{array}$ & 48.5 & 44.6 & 51.4 & 84.3 & 46.2 & 47.2 \\
\hline Fixed-term & 63.7 & 43 & 34.7 & 27.0 & 41 & 14.4 \\
\hline Part-time & 50.9 & 67.1 & 63.7 & 91.1 & 77.1 & 84.2 \\
\hline Self-employment & 24.5 & 17.1 & 30.7 & 13.6 & 11.4 & 21.3 \\
\hline Involuntary non-standard employment & 58 & 41.5 & 48.3 & 13 & 34.3 & 12.6 \\
\hline $\begin{array}{l}\text { Rate of non-standard work in } \\
\text { employment (men), of which: }\end{array}$ & 43.2 & 31.4 & 40 & 47.1 & 31 & 29.4 \\
\hline Fixed-term & 88.8 & 79 & 69.5 & 55.1 & 67 & 36.9 \\
\hline Part-time & 17.4 & 24.5 & 20.5 & 55.3 & 42 & 37 \\
\hline Self-employment & 44.6 & 44.3 & 64 & 38.1 & 38 & 62 \\
\hline Involuntary non-standard employment & 48.1 & 30.4 & 30.4 & 16.4 & 30.3 & 14.6 \\
\hline
\end{tabular}

Note: a Given the possible overlapping between different form of non-standard contracts, the sum of fixed term, part-time and self-employment is not equal to 100 .

Source: Authors' own elaboration from the European Labour Force Survey 
Table 3A.2: Indicators on part-time employment in the six countries population aged 15-64, percentages, 2016

\begin{tabular}{|c|c|c|c|c|c|c|}
\hline & $\begin{array}{l}\text {. } \\
\text { ñ }\end{array}$ & 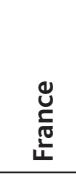 & $\underset{ \pm}{\frac{\lambda}{\pi}}$ & 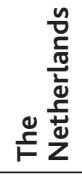 & 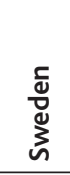 & 弚 \\
\hline Part-time employment (women) & 24.7 & 29.9 & 32.7 & 76.8 & 35.6 & 39.8 \\
\hline Part-time employment (men) & 7.5 & 7.7 & 8.2 & 26 & 13 & 10.9 \\
\hline Part-time employment (native) & 14.8 & 18 & 17.4 & 50.1 & 23.7 & 25 \\
\hline Part-time employment (migrant) & 19.4 & 24.8 & 28.2 & 42.7 & 27.1 & 20.5 \\
\hline Part-time employment (15-24) & 40.3 & 24.5 & 29.6 & 80.2 & 49.1 & 35.7 \\
\hline Part-time employment (25-34) & 18.3 & 15.4 & 22 & 40.6 & 21.9 & 18.4 \\
\hline Part-time employment (35-49) & 13.9 & 17.4 & 18.9 & 43.7 & 19.6 & 22.7 \\
\hline Part-time employment (50-64) & 11.6 & 20.6 & 14.6 & 47.5 & 21.3 & 26.9 \\
\hline Part-time employment (low education) & 17.1 & 25.4 & 19.4 & 58.5 & 34.4 & 27 \\
\hline Part-time employment (medium education) & 16.6 & 18.8 & 19.2 & 51.7 & 23.4 & 27.4 \\
\hline Part-time employment (high education) & 13.2 & 15.1 & 15.7 & 42.8 & 21.2 & 20.8 \\
\hline Overall total part-time employment & 15.3 & 18.4 & 18.5 & 49.8 & 23.9 & 24.5 \\
\hline $\begin{array}{l}\text { Rate of involuntary part-timers in } \\
\text { total part-time employment }\end{array}$ & 68.4 & 45.2 & 65.6 & 13.1 & 34.6 & 16.8 \\
\hline
\end{tabular}

Source: Authors' own elaboration from the European Labour Force Survey 
Table 3A.3a: Percent inactive by intersectional categories (age, gender and education), Spain and Italy

\begin{tabular}{|c|c|c|c|c|c|c|c|}
\hline \multirow[b]{2}{*}{ Young adult (25-34) } & \multicolumn{3}{|c|}{ Spain } & \multirow[b]{2}{*}{ Young adult (25-34) } & \multicolumn{3}{|c|}{ Italy } \\
\hline & Men & Women & Gaps & & Men & Women & Gaps \\
\hline Low educated & 40.1 & 50.7 & -10.6 & Low educated & 41.7 & 66 & -24.3 \\
\hline Medium educated & 30.6 (ns) & 35.7 & -5.1 & Medium educated & 29.5 & 45.5 & -16 \\
\hline High educated & 24.3 & 26.9 & -2.6 & High educated & 35.6 & 37.8 & -2.2 \\
\hline Totals by age & 31.8 & 34.7 & -2.9 & Totals by age & 33.9 & 46.7 & -12.8 \\
\hline Adult (35-49) & Men & Women & Gaps & Adult (35-49) & Men & Women & Gaps \\
\hline Low educated & 35.1 & 51.8 & -16.7 & Low educated & 25.4 & 59.4 & -34 \\
\hline Medium educated & 20 & 35.5 & -15.5 & Medium educated & 11.2 & 33.3 & -22.1 \\
\hline High educated & 12 & 22.4 & -10.4 & High educated & 6.3 & 16.8 & -10.5 \\
\hline Totals by age & 22.8 & 34.7 & -11.9 & Totals by age & 16.2 & 38.8 & -22.6 \\
\hline
\end{tabular}

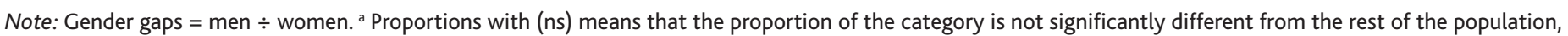
measured at .95 probability with a two-sample test of proportion. The overall significance test anova has confirmed that the difference in means by country and intersectional categories are statistically significant.

Source: Authors' own elaboration on the European Labour Force Survey (averages 2013-16) 
Table 3A.3b: Percent inactive by intersectional categories (age, education and number of children under 14 years old), Spain and Italy

\begin{tabular}{|c|c|c|c|c|c|c|c|c|c|c|c|}
\hline \multirow[b]{2}{*}{ Young adult (25-34) } & \multicolumn{5}{|c|}{ Spain } & \multirow[b]{2}{*}{ Young adult (25-34) } & \multicolumn{5}{|c|}{ Italy } \\
\hline & 0 & 1 & 2 & $3+$ & Total & & 0 & 1 & 2 & $3+$ & Total \\
\hline Low educated & -0.6 & -16.7 & -25.8 & -16.1 & -10.6 & Low educated & -12.3 & -29 & -41.9 & -45 & -24.3 \\
\hline Medium educated & -0.9 & -16.5 & -22.3 & -25.6 & -5.1 & Medium educated & -11.2 & -27 & -39.5 & -59.2 & -16 \\
\hline High educated & -0.6 & -12.3 & -17.3 & -42.4 & -2.6 & High educated & -2.2 & -15.6 & -16.5 & -30.8 & -2.2 \\
\hline Totals by age & 2.3 & -11.7 & -20.6 & -20.5 & -2.9 & Totals by age & -7.3 & -22 & -34.4 & -46.1 & -12.8 \\
\hline Adult (35-49) & 0 & 1 & 2 & $3+$ & Total & Adult (35-49) & 0 & 1 & 2 & $3+$ & Total \\
\hline Low educated & -5 & -24.8 & -33.2 & -33.7 & -16.7 & Low educated & -24.4 & -41 & -45.6 & -54.7 & -34 \\
\hline Medium educated & -7.3 & -20.9 & -24.2 & -23.9 & -15.5 & Medium educated- & -14.6 & -25.1 & -30.9 & -38.5 & -22.1 \\
\hline High educated & -4.1 & -14.2 & -15.9 & -16.4 & -10.4 & High educated & -5.3 & -13.7 & -15.4 & -19.2 & -10.5 \\
\hline Totals by age & -4.1 & -17.9 & -19.9 & 19.7 & -11.9 & Totals by age & -16.4 & -26.9 & -28.9 & -35.2 & -22.6 \\
\hline
\end{tabular}

Source: Authors' own elaboration on the European Labour Force Survey (averages 2013-16) 
Table 3A.4a:Worked hours (self-declared) ${ }^{\mathrm{a}}$ by intersectional categories (age, gender and education), Spain and Italy (averages) ${ }^{\mathrm{b}}$

\begin{tabular}{|c|c|c|c|c|c|c|c|}
\hline \multirow[b]{2}{*}{ Young adult (25-34) } & \multicolumn{3}{|c|}{ Spain } & \multirow[b]{2}{*}{ Young adult (25-34) } & \multicolumn{3}{|c|}{ Italy } \\
\hline & Men & Women & Gaps & & Men & Women & Gaps \\
\hline Low educated & 39.9 & 34 & 5.9 & Low educated & 40.2 & 32.1 & 8 \\
\hline Medium educated & 39.9 & 34.6 & 5.3 & Medium educated & 39.7 & 33.7 & 6 \\
\hline High educated & 38.9 & 35.1 & 3.8 & High educated & 38.6 & 33.9 & 4.7 \\
\hline Totals by age & 39.4 & 34.8 & 4.7 & Totals by age & 39.6 & 33.6 & 6 \\
\hline Adult (35-49) & Men & Women & Gaps & Adult (35-49) & Men & Women & Gaps \\
\hline Low educated & 42 & 32.5 & 9.5 & Low educated & 41.1 & 32.2 & 8.9 \\
\hline Medium educated & 41.7 & 35.1 & 6.6 & Medium educated & 41.1 & 33.1 & 8 \\
\hline High educated & 41.1 & 36.2 & 4.9 & High educated & 40 & 32.5 & 7.5 \\
\hline Totals by age & 41.5 & 35.1 & 6.5 & Totals by age & 40.9 & 32.7 & 8.2 \\
\hline
\end{tabular}

Notes: ${ }^{a}$ Using self-declared usual working time allows us to track the real working involvement of the person in the labour market, which might be different from what is officially stated in the contract (see, eg, bogus part-time work). ${ }^{b}$ The overall significance test anova has confirmed that the differences in means by country and intersectional categories are statistically significant. Means are all significant. Gender gaps $=$ men $\div$ women

Source: Authors' own elaboration on the European Labour Force Survey (averages 2013-16). 
Table 3A.4b: Gender gap in hours worked (self-declared) (men hours $\div$ women hours) by intersectional categories (age, education and number of children under 14 years old), Spain and Italy

\begin{tabular}{|c|c|c|c|c|c|c|c|c|c|c|c|}
\hline \multirow[b]{2}{*}{ Young adult (25-34) } & \multicolumn{5}{|c|}{ Spain } & \multirow[b]{2}{*}{ Young adult (25-34) } & \multicolumn{5}{|c|}{ Italy } \\
\hline & 0 & 1 & 2 & $3+$ & Total & & 0 & 1 & 2 & $3+$ & Total \\
\hline Low educated & 2.4 & 9 & 12.2 & 7.2 & 5.9 & Low educated & 6.2 & 9.3 & 10.6 & 11.2 & 8.1 \\
\hline Medium educated & 4 & 7.2 & 10 & 13.7 & 5.3 & Medium educated & 5 & 7.5 & 9.3 & 10.8 & 6 \\
\hline High educated & 3.2 & 6.8 & 5.5 & 5.5 & 3.8 & High educated & 3.7 & 7.6 & 10.5 & 8.7 & 4.7 \\
\hline Totals by age & 3.4 & 7.4 & 9.1 & 8.2 & 4.7 & Totals by age & 4.8 & 7.9 & 9.6 & 11 & 6 \\
\hline Adult (35-49) & 0 & 1 & 2 & $3+$ & Total & Adult (35-49) & 0 & 1 & 2 & $3+$ & Total \\
\hline Low educated & 8 & 10.1 & 12.6 & 9.5 & 9.5 & Low educated & 7.7 & 9.7 & 10.9 & 12.7 & 8.9 \\
\hline Medium educated & 4.5 & 7.6 & 8.9 & 8.2 & 6.6 & Medium educated & 5.9 & 8.7 & 10.5 & 11.3 & 8 \\
\hline High educated & 2.6 & 6.3 & 6.5 & 7.1 & 4.9 & High educated & 5.2 & 8.2 & 9.8 & 12.6 & 7.5 \\
\hline Totals by age & 4.6 & 7.6 & 8.1 & 7.5 & 6.5 & Totals by age & 6.3 & 8.9 & 10.4 & 12.2 & 8.2 \\
\hline
\end{tabular}

Source: Authors' own elaboration on the European Labour Force Survey (averages 2013-16) 
Table 3A.5: Characteristics of standard and non-standard employment by involuntariness, 25-49 years old, Spain and Italy (percentages)

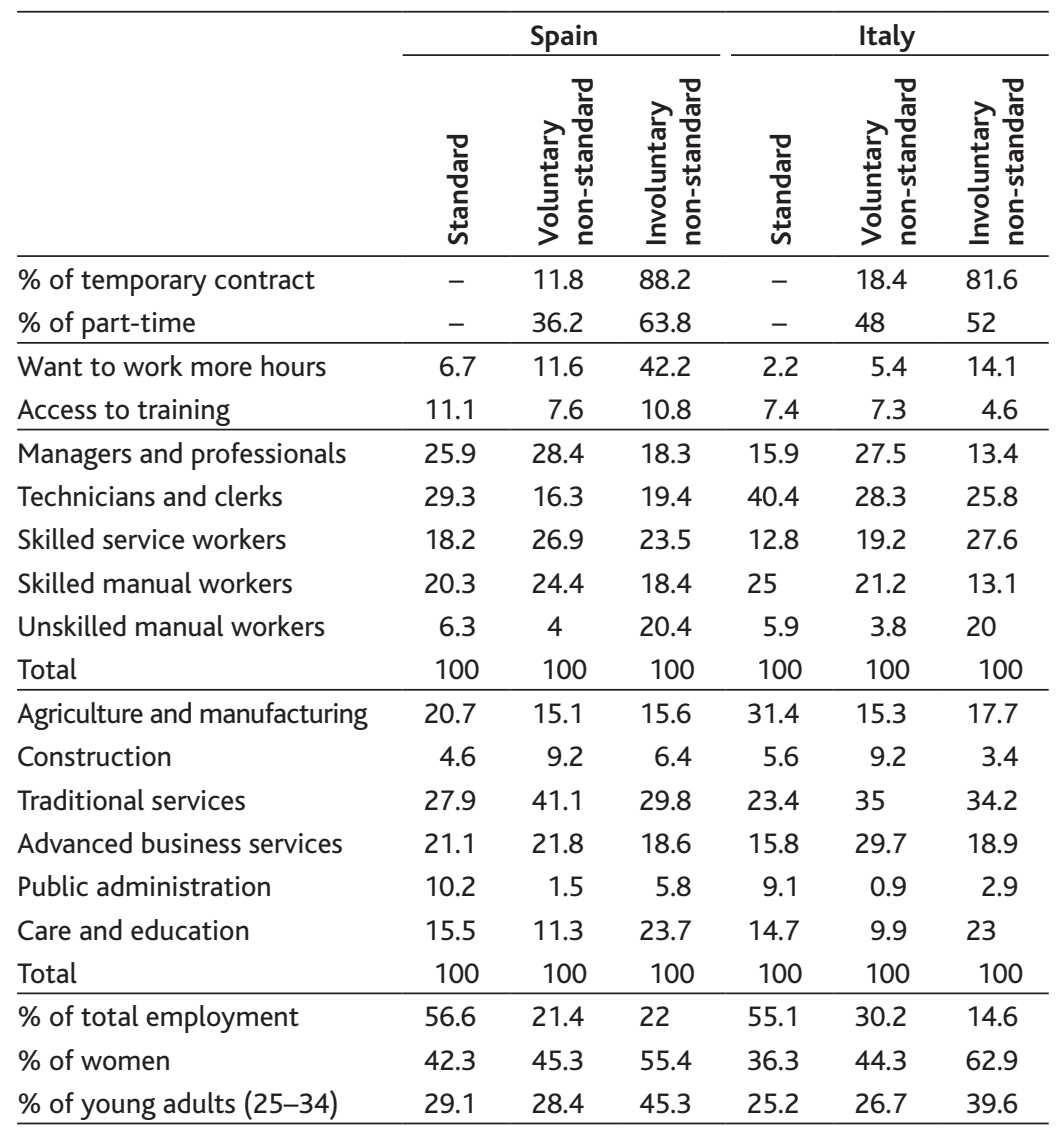

Source: Authors' own elaboration on the European Labour Force Survey (averages 2013-16) 
Table 3A.6: Percentages of workers that declared to be involuntary parttimers by intersectional categories (gender, age and education), Spain and Italy

\begin{tabular}{llllcc}
\hline & \multicolumn{3}{c}{ Spain } & & \multicolumn{2}{c}{ Italy } \\
\cline { 2 - 3 } \cline { 6 - 7 } Young adult (25-34) & $\mathbf{M}$ & $\mathbf{F}$ & & $\mathbf{M}$ & $\mathbf{F}$ \\
\hline Low educated & 86.4 & 71.8 & & 89.8 & 75.2 \\
Medium educated & $68.3(\mathrm{~ns})$ & 65.1 & 85.2 & 66.6 \\
High educated & 75.9 & 69.9 & 81.7 & 70.2 \\
Rate of part-time employment in the age class & 11 & 25 & 9.7 & 31.8 \\
\hline Adult (35-49) & $\mathbf{M}$ & $\mathbf{F}$ & $\mathbf{M}$ & $\mathbf{F}$ \\
\hline Low educated & 81 & 67.4 & 86.4 & 64.8 \\
Medium educated & 75.7 & 53.5 & 76.1 & 44 \\
High educated & 69.3 & 41.9 & 68.2 & 42.8 \\
Rate of part-time employment in the age class & 4.9 & 24.1 & 5.3 & 32.8 \\
\hline
\end{tabular}

Notes: a Proportions with (ns) mean that the proportion of the category is not significantly different from the rest of the population, measured at .95 probability with a two-sample test of proportion. The overall significance test anova has confirmed that the differences in means by country and intersectional categories are statistically significant.

Source: Authors' own elaboration on the European Labour Force Survey (averages 2013-16) 